\title{
The relative potency of the Crick-Harper-Raper unit and the GIH clinical unit of secretin
}

\author{
JOAN M. BRAGANZA, HENRY T. HOWAT, AND G. KAY \\ From the University Department of Gastroenterology, Manchester Royal Infirmary
}

SUMMARY A reinvestigation of the relationship between the Crick-Harper-Raper (CHR) and the GIH clinical units (CU) of secretin has been undertaken in anaesthetized cats with the knowledge that for some time before 1970 the CHR standard used by The Boots Company to assay secretin had lost some specific activity. One clinical unit of GIH secretin (batch no. 17421) is 3.8 times more potent than 1 Crick-Harper-Raper unit of restandardized Boots secretin (batch no. 142) in increasing the flow rate of pancreatic juice, and four times more potent in increasing the amount of bicarbonate.

In 1970, when reviewing the results of secretinpancreozymin tests done in Manchester Royal Infirmary (Burton, Evans, Harper, Howat, Oleesky, Scott, and Varley, 1960), it was apparent that the mean volume of duodenal contents after secretin had fallen. Since the technique had varied little over the years the possibility of deterioration in the secretin used was considered. We have learned from Mr Birkenshaw, Head of Bioassay of The Boots Company Ltd, (Birkenshaw, 1974, personal communication) that a gradual unsuspected deterioration in the original secretin standard had resulted before 1970 in batches possessing less activity than indicated on the label. The potency of the reference preparations has since been re-established so that batches no. 119 onwards have been standardized to the original CHR unit. It was necessary to compare afresh the relative potency of the units of these two commonly available preparations of secretin currently used in clinical medicine. The study was undertaken in June 1974.

\section{Methods}

\section{SECRETINS}

A sample of Boots secretin (batch no. 142) was purchased from The Boots Company Ltd, Nottingham, England. Each rubber-capped vial contained 100 Crick-Harper-Raper units of secretin (Crick, Harper, and Raper, 1949), A sample of GIH secretin (batch no. 17421) was purchased from the Gastrointestinal Hormone Research Unit of the Karolinska Institute, Stockholm, Sweden. Each allReceived for publication 21 April 1975. glass ampoule contained 75 clinical units (CU) of highly purified secretin to which is added $1 \mathrm{mg}$ of cysteine hydrochloride to preserve activity (Jorpes and Mutt, 1973). Boots secretin was stored at $4^{\circ} \mathrm{C}$ and GIH secretin at $-20^{\circ} \mathrm{C}$. Immediately before use both preparations were dissolved in sterile normal saline at room temperature to provide a concentration of $2 \mathrm{CHR}$ units/ml of Boots secretin and $0.5 \mathrm{CU} / \mathrm{ml}$ of $\mathrm{GIH}$ secretin.

\section{EXPERIMENTAL PROCEDURES}

Four cats weighing $2 \cdot 7,2 \cdot 3,2 \cdot 6$, and $3.0 \mathrm{~kg}$ were fasted for 24 hours before the experiments, anaesthetized, and prepared according to the technique of Howat and Schofield (1954). The splanchnic nerves were divided extraperitoneally. The pancreatic duct was cannulated, and the common bile duct obliterated by the ligature retaining the cannula. The pylorus was occluded by a broad tape ligature.

Since a preliminary experiment indicated that 1 CHR unit of Boots secretin was approximately four times less potent than one $\mathrm{CU}$ of GIH secretin (fig 1), rapid intravenous injections of 1 and 2 CHR units $/ \mathrm{kg}$ of Boots secretin and 0.25 and $0.5 \mathrm{CU} / \mathrm{kg}$ of GIH secretin were used in each cat. The order of administration of the secretins was determined by a $2 \times 2$ Latin square arrangement, with the restrictions of equal numbers of observations per dose, equal numbers of doses per substance, equal logarithmic spacing of the doses, and that the higher doses of the two secretins were not given consecutively.

Observations were recorded at 15 -minute intervals and 30 to 45 minutes were allowed to elapse between 


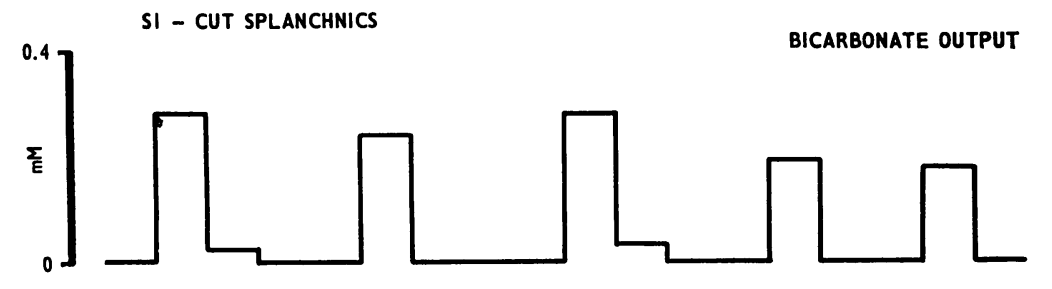

Fig 1 The volume of pancreatic juice and the bicarbonate output per 15 minutes in response to intravenous injections of Boots and GIH secretin.

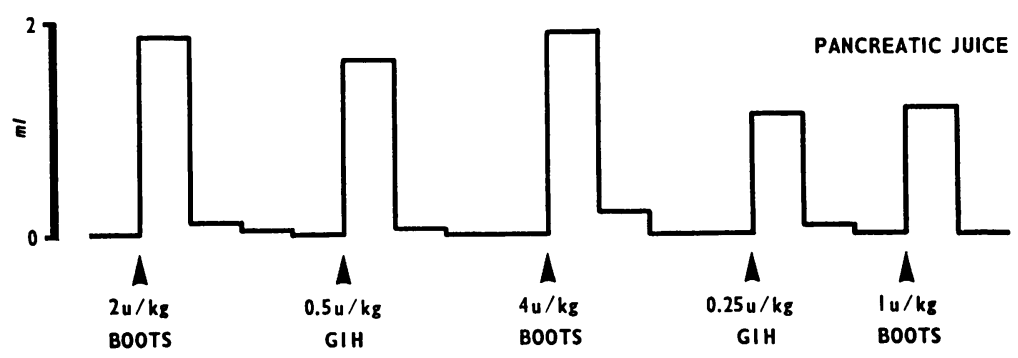

injections. The volume of pancreatic juice was recorded to the nearest $0.01 \mathrm{ml}$. Bicarbonate concentration was measured by back titration after treatment with $0 \cdot 1 \mathrm{~N} \mathrm{HCl}$.

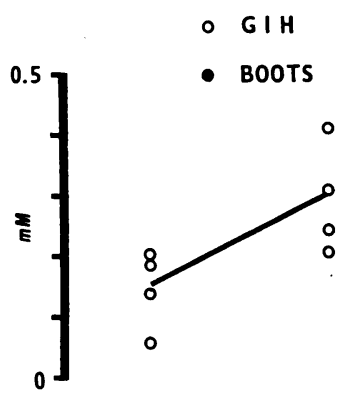

BICARBONATE OUTPUT
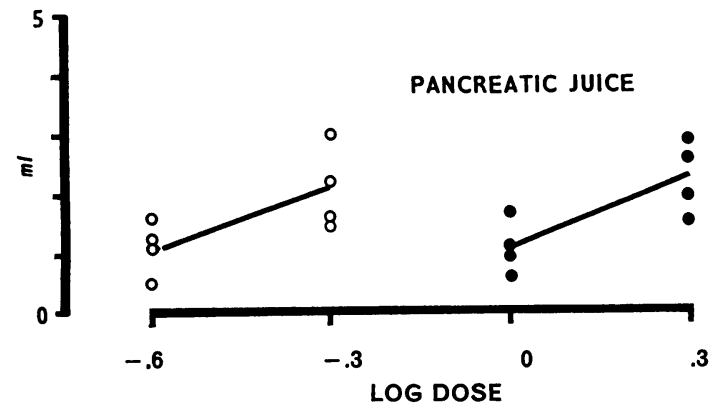

Fig $2 A 2 \times 2$ assay of the relative potency of $1 C H R$ unit and $1 C U$ of secretin in increasing the volume of pancreatic juice and the bicarbonate output.
Tests of dependence, linearity, and parallelism were applied to the data for volume and bicarbonate output, and the relative potency of the CHR and the CU was estimated (Emmens, 1948).

\section{Results}

A preliminary analysis using three doses of GIH secretin $(0.125,0.25,0.5 \mathrm{CU} / \mathrm{kg})$ and three doses of Boots secretin $(0.5,1.0,2.0 \mathrm{CHR} \mathrm{u} / \mathrm{kg})$ showed that a linear equation significantly described the relationship between log dose and volume of pancreatic juice or bicarbonate output in each instance. A four-point assay was therefore used (Emmens, 1948).

The log-dose response lines for Boots and GIH secretin were parallel for both volume of juice and bicarbonate output (table I, fig 2).

A comparison of the relative potency of the GIH clinical unit and the CHR unit of Boots secretin, as specified on the labels, yielded a ratio of $3 \cdot 8: 1$ for rate of flow and $4: 1$ for bicarbonate (table).

\section{Discussion}

Theoretically, the best way to standardize secretin would be to compare the preparation against a synthetic standard unit. Unfortunately the biological activity of even pure secretins is difficult to preserve in storage. Synthetic secretin appears to be equally labile.

Ivy and his coworkers (Ivy and Oldberg, 1928a, 1929b; Ivy, Kløster, Drewyer, and Lueth, 1930) used the anaesthetized dog to assay the biological activity 


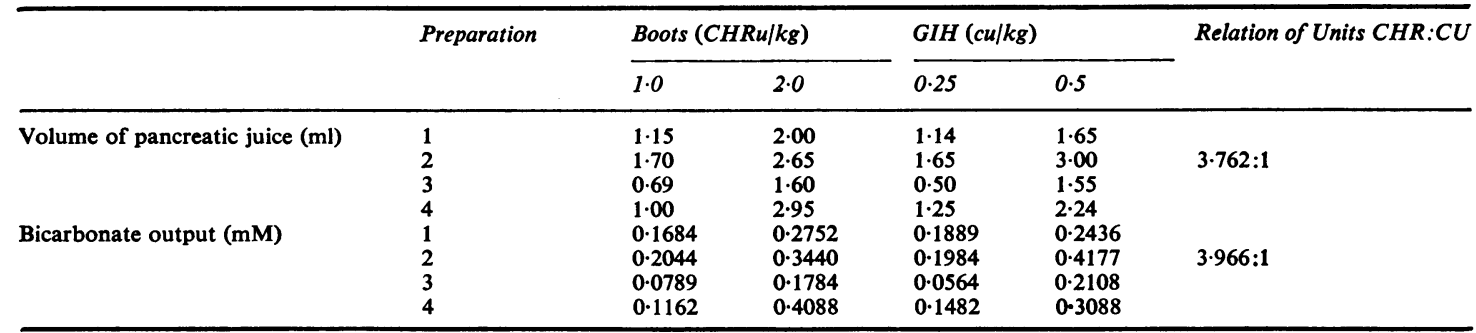

Table Volume of pancreatic juice and bicarbonate output in response to two doses of Boots and two doses of GIH secretin in each of four cats

of secretin. In the fasting dog, however, the pancreas secretes spontaneously which may subject the bioassay to error. The pancreas of the fasting cat does not secrete spontaneously. Crick et al (1949), who used fed cats in order to ensure that the pancreas was highly responsive to secretin, noted, especially towards the end of their experiments, a gradual decrease in the response to secretin and suggested that for the routine assay of both secretin and pancreozymin the less sensitive but less variable fasting animal might be preferred. We have therefore employed fasting animals but with splanchnic nerves sectioned to remove their inhibitory influence on the pancreas (Harper and Vass, 1941). Although anaesthesia itself may contribute to the variation in responses (Crick et al, 1949), the advantages of pyloric and bile duct occlusion which prevents the release of either stimulating or inhibiting duodenal hormones outweigh this consideration.

Hammerstein, Wilander, and Ågren (1928) based their secretin assay on the amount of alkali produced in cats, whereas the Ivy group measured the volume of secretion in dogs. Harper (1967) has shown that in cats when rates of flow exceed a minimum level of $1.0 \mathrm{ml} / 10 \mathrm{~min}$ in response to a single intravenous injection of secretin the concentrations of bicarbonate and chloride are constant at about 140 and $24 \mathrm{mM}$ per litre respectively, but that at lower rates of flow the bicarbonate concentration decreases and the chloride increases in inverse fashion due to exchange of these ions within the duct, the sum of the two remaining constant. A comparison of bicarbonate outputs when the volume is less than $1 \mathrm{ml} / 10 \mathrm{~min}$ may therefore be a less reliable index than rates of flow, since in these circumstances small differences in the volume of pancreatic juice may be associated with relatively large differences in bicarbonate concentration and output.

Lagerlöf (1942) introduced the concept of the clinical unit as that amount of secretin per kilogram which in man elicits an adequate pancreatic response and initially equated 1 clinical unit of Pancreotest
(Astra) to 16 Hammersten cat units (HCU). Greengard and Stein (1941) noted that 1 dog threshold unit of Ivy corresponded to 1 clinical unit of Pancreotest, and Greengard and Ivy (1938) found that 1 Ivy dog threshold unit was equivalent to $20 \mathrm{HCU}$. Jorpes and Mutt (1966) decided that it was convenient to conclude that 1 clinical unit approximated 20, not 16, HCU. Between 1958 and 1965, when secretin was manufactured by Vitrum, the clinical unit was assumed to equal the clinical unit of Pancreotest. Jorpes and Mutt observed, however, that the potency of the Vitrum clinical unit during this period was appreciably less than the original Pancreotest (Astra) preparations. They undertook the production of secretin at the Gastrointestinal Hormone Research Unit, Stockholm, and decided to upgrade the potency of secretin by a factor of 4 from batch 16611 (Jorpes and Mutt, 1973), so that 'the current clinical unit probably equals that of the old Pancreotest (Astra) unit with which Lagerlöf (1942) elaborated the secretin test of pancreatic function' (Zimmerman, Dreiling, and Janowitz, 1973).

Crick et al (1949) defined their unit of secretin as the activity present in $0.1 \mathrm{mg}$ of an arbitbrarily chosen standard preparation which yielded a mean of 1.2 $\mathrm{ml}$ in $12 \mathrm{~min}$; Jorpes and Mutt (1966) estimated that $1 \mathrm{CHR}$ unit was about $12 \mathrm{HCU}$, or approximately half a clinical unit of Pancreotest (taking $1 \mathrm{CU}=$ $20 \mathrm{HCU})$. An intravenous injection of 1 clinical unit/kg of Pancreotest (Astra) in man produced an average of $135 \mathrm{ml}$ of juice in 30 minutes (Lagerlöf, 1942) while $1.7 \mathrm{CHR}$ units/kg of Boots secretin produced $136 \pm 6 \cdot 2 \mathrm{ml}$ (mean $\pm \mathrm{SE}$ of mean) in 30 minutes (Burton et al, 1960). Thus 1 CHR unit equals 0.58 clinical units of Pancreotest, justifying the conclusion of Jorpes and Mutt (1966).

The relatively greater potency of the unit of GIH secretin when compared with the unit of Boots secretin in terms of bicarbonate, 3.96:1, than in terms of volume $3 \cdot 76: 1$, cannot be explained by an increased amount of pancreozymin in Boots secretin (Harper, 1967). In our experiments the concentra- 
tions of chloride and lipase in response to $1 \mathrm{CHR}$ $\mathrm{u} / \mathrm{kg}$ Boots secretin do not differ from those obtained in response to $0.25 \mathrm{CU} / \mathrm{kg}$ GIH secretin nor do they differ in response to $2 \mathrm{CHR} \mathrm{u/kg} \mathrm{Boots} \mathrm{secretin} \mathrm{and}$ $0.5 \mathrm{CU} / \mathrm{kg}$ GIH secretin $(\mathrm{t}=0.7<\mathrm{P}<0.8$ in each case). In one experiment the mean peak concentration of lipase in response to $4 \mathrm{CHR} \mathrm{u} / \mathrm{kg} / \mathrm{hr}$ Boots secretin was $9.35 \mathrm{IU} / \mathrm{ml}$ and in response to $1 \mathrm{CU} / \mathrm{kg} /$ $\mathrm{hr}$ GIH secretin was $10.35 \mathrm{IU} / \mathrm{ml}$, the chloride concentration being $30 \mathrm{mM}$ and $38 \mathrm{mM}$ /litre respectively. We conclude therefore that neither of the batches of secretin used in these experiments contained a significant quantity of cholecystokininpancreozymin.

Reports that 1 CHR unit of Boots secretin was nine to 10 times less potent than $1 \mathrm{CU}$ of GIH secretin in stimulating the pancreas in cats (Konturek, 1969), dogs (Stening, Vagne, and Grossman, 1968), and man (Vagne, Descos, and Martin, 1969) were therefore unexpected. We have been informed that the Boots preparation during the period of these reports fell below standard. Our experiments in cats show that the revised clinical unit of GIH secretin is four times more potent than the restandardized CHR unit of Boots secretin. This may mean that the fourfold increase in strength applied by Jorpes and Mutt to GIH secretin has yielded a clinical unit approximately twice as potent as the original clinical unit of Pancreotest (Lagerlöf, 1942).

From our data in cats (fig 1) doubling the dose of Boots secretin from 2 to 4 CHR units $/ \mathrm{kg}$ does not increase the volume or bicarbonate output of pancreatic juice. At present we employ a submaximal dose of 2 CHR units/kg secretin in the secretinpancreozymin test which we consider provides an adequate stimulus within the physiological range for clinical diagnostic purposes. The use of 1 to 2 clinical units/kg GIH secretin as proposed by Jorpes and Mutt (1973) is maximal or near maximal stimulation of the exocrine pancreas.

We are indebted to Professor A. A. Harper for his critical appraisal of the manuscript. We thank Mr A. C. C. Gibbs of the Department of Social Medicine, University of Manchester, for statistical advice, and Dr R. G. Ollerenshaw of the University Department of Medical Illustration.
References

Burton, P., Evans, D. G., Harper, A. A., Howat, H. T., Oleesky, S., Scott, J. E., and Varley, H. (1960). A test of pancreatic function in man based on the analysis of duodenal contents after administration of secretin and pancreozymin. Gut, 1, 111-124.

Crick, J., Harper, A. A., and Raper, H. S. (1949). On the preparation of secretin and pancreozymin. J. Physiol. (Lond.), 110, 367-376.

Emmens, C. W. (1948). Principles of Biological Assay, pp. 88-97. Chapman and Hall, London.

Greengard, H., and Ivy, A. C. (1938). The isolation of secretin. Amer. J. Physiol., 124, 427-434.

Greengard, H., and Stein, I. F., Jr. (1941). Assay of secretin. Proc. Soc. exp. Biol. (N.Y.), 46, 149-151.

Hammersten, E., Wilander, O., and Ågren, G. (1928). Versuche zur Reinigung von Sekretin. Acta med. scand., 68, 239-247.

Harper, A. A. (1967). Hormonal control of pancreatic secretion. In Handbook of Physiology, pp. 969-996. Sect. 6, edited by C. F. Code, Vol. II. American Physiological Society. Washington, D.C.

Harper, A. A., and Vass, C. C. N. (1941). The control of the external secretion of the pancreas in cats. J. Physiol. (Lond.), 99, 415435.

Howat, H. T., and Schofield, B. (1954). The effect of urogastrone, enterogastrone, and mepyramine maleate on gastric and pancreatic secretion. J. Physiol. (Lond.), 123, 1-15.

Ivy, A. C., Kloster, G., Drewyer, G. E., and Lueth, H. C. (1930) The preparation of a secretin concentrate. Amer. J. Physiol., 95, 35-39.

Ivy, A. C., and Oldberg, E. (1928a). Contraction and evacuation of the gall bladder by a purified 'secretin' preparation. J. Amer. med. Ass., 90, 445-446.

Ivy, A. C., and Oldberg, E. (1928b). Hormone mechanism for gall bladder contraction and evacuation. Amer.J. Physiol., 86, 599. 613.

Jorpes, J. E., and Mutt, V. (1966). On the biological assay of secretin: the reference standard. Acta physiol. scand., 66, 316-325.

Jorpes, J. E., and Mutt, V., Eds. (1973). Secretin, Cholecystokinin, Pancreozymin and Gastrin, by M, Bodansky et al, p. 141. Springer, Berlin.

Konturek, S. J. (1969). Comparison of pancreatic responses to natural and synthetic secretins in conscious cats. Amer. J. dig. Dis., 14, $557-565$.

Lagerlöf, H. (1942). Pancreatic function and pancreatic disease studied by means of secretin. Acta med. scand., Suppl. 128.

Stening, G. F., Vagne, M., and Grossman, M. I. (1968). Relative potency of commercial secretins. Gastroenterology, 55, 687-689.

Vagne, M., Descos, L., and Martin, P. (1969). La sécrétion bicarbonatée maximum du pancréas humain. C.R. Soc. Biol. (Paris), 163, 1403-1406.

Zimmerman, M. J., Dreiling, D. A., and Janowitz, H. D. (1973). In Secretin, Cholecystokinin, Pancreozymin and Gastrin, by $\mathbf{M}$ Bodansky et al, edited by J. E. Jorpes and V. Mutt, p. 219. Springer, Berlin.

\section{Addendum}

Since submitting this paper for publication, we have seen the report of Boden, Dinoso, and Owen in Gastroenterology $(67,1119-1125,1974)$ who have found that the immunological potency of 1 clinical unit of GIH secretin is equivalent to 4 CHR units of Boots secretin. 